\title{
Marijuana Withdrawal in Humans: Effects of Oral THC or Divalproex
}

\author{
Margaret Haney*,', Carl L Hart', Suzanne K Vosburg', Jennifer Nasser', Andrew Bennett', Carlos Zubaran' \\ and Richard W Foltin' \\ 'Division on Substance Abuse, New York State Psychiatric Institute, Department of Psychiatry, College of Physicians and Surgeons of Columbia \\ University, New York, NY, USA
}

\begin{abstract}
Abstinence following daily marijuana use can produce a withdrawal syndrome characterized by negative mood (eg irritability, anxiety, misery), muscle pain, chills, and decreased food intake. Two placebo-controlled, within-subject studies investigated the effects of a cannabinoid agonist, delta-9-tetrahydrocannabinol (THC: Study I), and a mood stabilizer, divalproex (Study 2), on symptoms of marijuana withdrawal. Participants $(n=7 /$ study), who were not seeking treatment for their marijuana use, reported smoking 6-10 marijuana cigarettes/day, 6-7 days/week. Study I was a I5-day in-patient, 5-day outpatient, I5-day in-patient design. During the in-patient phases, participants took oral THC capsules $(0,10 \mathrm{mg})$ five times/day, I h prior to smoking marijuana $(0.00,3.04 \%$ THC). Active and placebo marijuana were smoked on in-patient days $\mid-8$, while only placebo marijuana was smoked on days 9-14, that is, marijuana abstinence. Placebo THC was administered each day, except during one of the abstinence phases (days 9-14), when active THC was given. Mood, psychomotor task performance, food intake, and sleep were measured. Oral THC administered during marijuana abstinence decreased ratings of 'anxious', 'miserable', 'trouble sleeping', 'chills', and marijuana craving, and reversed large decreases in food intake as compared to placebo, while producing no intoxication. Study 2 was a 58-day, outpatient/in-patient design. Participants were maintained on each divalproex dose $(0,1500 \mathrm{mg} /$ day) for 29 days each. Each maintenance condition began with a 14 -day outpatient phase for medication induction or clearance and continued with a 15-day in-patient phase. Divalproex decreased marijuana craving during abstinence, yet increased ratings of 'anxious', 'irritable', 'bad effect', and 'tired.' Divalproex worsened performance on psychomotor tasks, and increased food intake regardless of marijuana condition. Thus, oral THC decreased marijuana craving and withdrawal symptoms at a dose that was subjectively indistinguishable from placebo. Divalproex worsened mood and cognitive performance during marijuana abstinence. These data suggest that oral THC, but not divalproex, may be useful in the treatment of marijuana dependence. Neuropsychopharmacology (2004) 29, I58-170, advance online publication, I5 October 2003; doi: I0.1038/sj.npp. I3003 I0
\end{abstract}

Keywords: marinol; depakote; dependence; withdrawal; treatment

\section{INTRODUCTION}

Dependence on marijuana is increasingly gaining recognition as a clinically significant phenomenon. Marijuana smokers are seeking treatment, particularly when marijuana-specific treatment programs are offered (Roffman et al, 1988; Stephens et al, 1993), and demand for treatment is on the rise (SAMHSA, 1999). Treatment-seekers report substantial distress about their marijuana use, but they repeatedly fail in their attempts to quit. Failure to quit is borne out by clinical studies, demonstrating that marijuana users have high rates of relapse comparable to those found for other drugs of abuse (Copeland et al, 2001; Stephens

*Correspondence: Dr M Haney, Associate Professor of Clinical Neuroscience, New York State Psychiatric Institute, College of Physicians and Surgeons of Columbia University, I05 I Riverside Drive, Unit 120, New York, NY 10032, USA, Tel: + I 212543 6539; Fax: + | 212543 599|; E-mail: mh235@columbia.edu

Received 27 May 2003; revised 28 July 2003; accepted 06 August 2003 Online publication: 14 August 2003 at http://www.acnp.org/citations/ Npp08 | 40303238/default/pdf et al, 1994, 2000). Adding voucher-based incentive programs to cognitive or motivational techniques appears to improve treatment compliance, as is the case for cocaine treatment (Budney et al, 2000). The one double-blind, clinical study testing a medication (divalproex) for marijuana dependence showed that few patients were able to maintain abstinence regardless of medication dose (Levin et al, 2003). Thus, marijuana dependence appears to be as difficult to treat as other drug dependencies. The fact that a large number of patients in treatment fail to achieve abstinence indicates that more options for marijuana dependence are needed.

We hypothesize that one impediment to maintaining abstinence from marijuana is the presence of withdrawal symptoms. A variety of laboratory and clinical studies have demonstrated in recent years that 'heavy' marijuana users, that is, those who smoke marijuana repeatedly each day, 67 days per week, experience a time-dependent set of withdrawal symptoms when abstaining from marijuana. We have shown in a laboratory model of marijuana withdrawal that abstinence following four to five marijuana 
cigarettes/day for 3-4 days was associated with decreased food intake, increased stomach upset, anxiety, irritability, and sleep difficulty. Symptoms were alleviated by the resumption of marijuana smoking, demonstrating the pharmacological specificity of marijuana withdrawal (Haney et al, 1999b; Hart et al, 2002b). These in-patient data were collected in individuals who were not seeking treatment for their marijuana use, yet a closely similar pattern of symptoms has been reported in outpatient volunteers attempting to quit marijuana. Treatment-seekers $(85 \%)$ reported increased irritability, aggressive behavior, depression, nervousness, and craving, and many of these individuals $(65 \%)$ reported using marijuana to alleviate withdrawal symptoms (Budney et al, 1999). Symptoms of marijuana withdrawal typically emerged after 1-2 days of abstinence, and largely resolved within 10 days (Boyd et al, 2002; Budney et al, 1998, 2001, 2002; Kouri and Pope, 2000; Stephens et al, 1993, 2000). The consistency in symptoms between these various studies, despite substantial differences in design and study population, is noteworthy.

Given that marijuana withdrawal plays a role in relapse to marijuana smoking, one approach to expanding treatment options for marijuana smokers is to decrease symptoms of withdrawal. This rationale has been used successfully in the treatment of tobacco smoking (see Shiffman et al, 2000) and opiate dependence (Dole, 1988). To date, we have tested the effects of two antidepressant medications on marijuana withdrawal: nefazodone $(0,450 \mathrm{mg} /$ day $)$ and sustainedrelease bupropion $(0,300 \mathrm{mg} /$ day $)$. Marijuana smokers were maintained on each dose of antidepressant for 4 weeks, and the effects of the maintenance condition on both the direct effects of marijuana and on marijuana withdrawal were assessed. Compared to placebo, nefazodone maintenance decreased a subset of marijuana withdrawal symptoms, such as, anxiety and muscle pain (Haney et al, 2003), while bupropion maintenance worsened mood during marijuana withdrawal compared to placebo: participants were more irritable, miserable, and depressed while maintained on bupropion during withdrawal than placebo (Haney et al, 2001).

The focus of the current studies was to determine if either a cannabinoid agonist, oral THC, or a mood stabilizer, divalproex, would attenuate a broader range of marijuana withdrawal symptoms than the antidepressants. The rationale for using a cannabinoid agonist such as THC to treat marijuana dependence in Study 1 is comparable to the rationale for using the opioid agonist, methadone, to treat opioid dependence. There are a number of important similarities between methadone and oral THC: both have a slow onset and a long duration of action compared to heroin or smoked marijuana. As a slow-acting agonist, oral THC is predicted to decrease craving and symptoms of marijuana withdrawal at doses that produce minimal intoxication. One important caveat is that unlike methadone, we do not envision long-term, clinical maintenance on oral THC, but rather a finite period of treatment to decrease withdrawal and craving, followed by a slow taper off oral THC.

The rationale for testing divalproex in Study 2 was that it has been used to treat irritability, mood lability, and temper outbursts (Donovan et al, 2000; Giakas et al, 1990), which are similar to symptoms of marijuana withdrawal. Dival- proex has also been shown to decrease irritability in alcoholics (Brady et al, 2002), and has been used to treat symptoms of alcohol and benzodiazepine withdrawal, including anxiety, insomnia, and nausea (Apelt and Emrich, 1990). These data suggest that divalproex may also be useful in the treatment of marijuana withdrawal.

For both studies, each in-patient phase in the laboratory had three marijuana conditions: a baseline condition, an active marijuana condition, and an abstinence condition, when only placebo marijuana was smoked. For Study 1, regular marijuana smokers were maintained as in-patients on two occasions: during one in-patient phase, placebo THC was administered during marijuana abstinence, and in another phase, oral THC was administered using a counterbalanced design. A 5-day outpatient phase separated the two in-patient phases to allow for THC clearance. For Study 2, marijuana smokers were first maintained outpatient on either placebo or active divalproex. Once steady state was attained, participants moved into the laboratory where they continued to take the same dose of divalproex throughout the entire in-patient phase, across each marijuana condition. Participants then crossed over to the alternate divalproex dose and the outpatient and in-patient study phases were repeated.

\section{METHODS: STUDY 1}

\section{Participants}

Seven male research volunteers (mean age $( \pm$ SD) $=24 \pm 1$ years) completed the 35-day experiment. An additional group of four male volunteers started but did not complete the study: one had a custody court date, one did not like the food options, one reported stomach discomfort during marijuana withdrawal (and placebo THC maintenance), and one had an abnormal EKG during marijuana withdrawal (and placebo THC maintenance).

Prior to study participation, volunteers provided a detailed drug and medical history, received complete medical and psychiatric evaluations shortly before study onset, and gave written informed consent for all aspects of the study. Those who completed the study reported smoking 9.6 $( \pm 6.2)$ marijuana cigarettes per day, 6.2 $( \pm 1.3)$ days per week. Six participants also reported drinking alcohol weekly $(2.3 \pm 1.5$ days/week, $2.7 \pm 1.5$ drinks/occasion). Six smoked tobacco cigarettes, and continued to do so during the experiment. Other drug use was infrequent. One participant reported weekly intranasal cocaine use, but was able to maintain abstinence for the duration of the study, confirmed by frequent urine toxicologies. Participants who did not diet were within accepted weight ranges for their heights $(71.5 \pm 7.7 \mathrm{~kg})$, and had no self-reported eating abnormalities.

Participants were instructed that the study investigated how medications influence the effects of marijuana. They were told that they may receive an antidepressant, an anticonvulsant, a medication to increase appetite, or a placebo. They were also told that the strength of the medication and marijuana cigarettes might change at any time throughout the study. Prior to discharge, participants were fully informed about the experimental and drug 
conditions. The New York State Psychiatric Institute's Institutional Review Board approved all procedures.

\section{Laboratory}

Participants, in three groups of three or four, lived in a residential laboratory designed for the continuous observation of human behavior over extended periods of time. The residential laboratory consists of 11 rooms in the New York State Psychiatric Institute: four private participant rooms, a common recreational area, two single-occupancy bathrooms, two single-occupancy shower rooms, and two vestibules used for exchanging supplies (see Haney et al, 1999a, for a more detailed description).

Output from a video- and audio-monitoring system terminated in an adjacent room. Participants were observed continuously, except while in the bathroom or in private dressing areas, although no recordings were made. Participants and staff communicated using a networked computer system, linking each participant's computer with the computer in the control room, and allowing for a continuous on-line interaction between participants and staff, but not between participants.

\section{Procedure}

Prior to study onset, participants received two training sessions (3-4 h/session) on the computerized tasks, and two predosing sessions: a dose of oral THC $(10 \mathrm{mg})$ was administered during one predosing session, and an active marijuana cigarette $(3.04 \%$ THC) was smoked during the other. As shown in Table 1, the study comprised two inpatient phases and one outpatient phase: an initial 15-day in-patient phase, a 5-day outpatient phase, and another 15day in-patient phase. During the outpatient phase, partici- pants were instructed to abstain from illicit drugs (excluding marijuana, for which no instructions were given). The purpose of the outpatient phase between the two in-patient phases was to allow for clearance of oral THC. Marijuana and oral THC administration was double-blind, and active oral THC administration was counterbalanced across participants. The active dose was hypothesized to be well tolerated and to ameliorate withdrawal symptoms without producing intoxication, based on our previous experience administering oral THC to marijuana smokers (Haney et al, 1999a, 2003; Hart et al, 2002a, b).

Participants received additional training on tasks and experimental procedures on the day they moved into the laboratory. The first experimental day began at 0815 the following morning. Each morning, participants completed a seven-item visual analog scale (VAS) sleep questionnaire (modified from the St Mary's Hospital Sleep Questionnaire; Ellis et al, 1981), consisting of 100-mm lines anchored with 'not at all' at the left end and 'extremely' at the right end, labeled with: 'I slept well last night', 'I woke up early this morning', 'I fell asleep easily last night', 'I feel clear-headed this morning', 'I woke up often last night', 'I am satisfied with my sleep last night', and a fill-in question estimating how many hours they slept the previous night. Participants then completed a 50-item VAS, measuring a range of moods and physical symptoms (described in Haney et al, 1999b), and were weighed and given time to eat breakfast. The first of seven 30-min task batteries composed of five performance measures (described below) and the VAS began at 0915. Participants took the first daily capsule at 0900 , and smoked their first marijuana cigarette of the day at 1000 . They completed two task batteries from 1015 to 1145, each consisting of the same five tasks and the VAS. Participants took their second capsule at 1200 , and had access to activities available in the recreation area from 1200 to 1250 .

Table I Study I Timeline

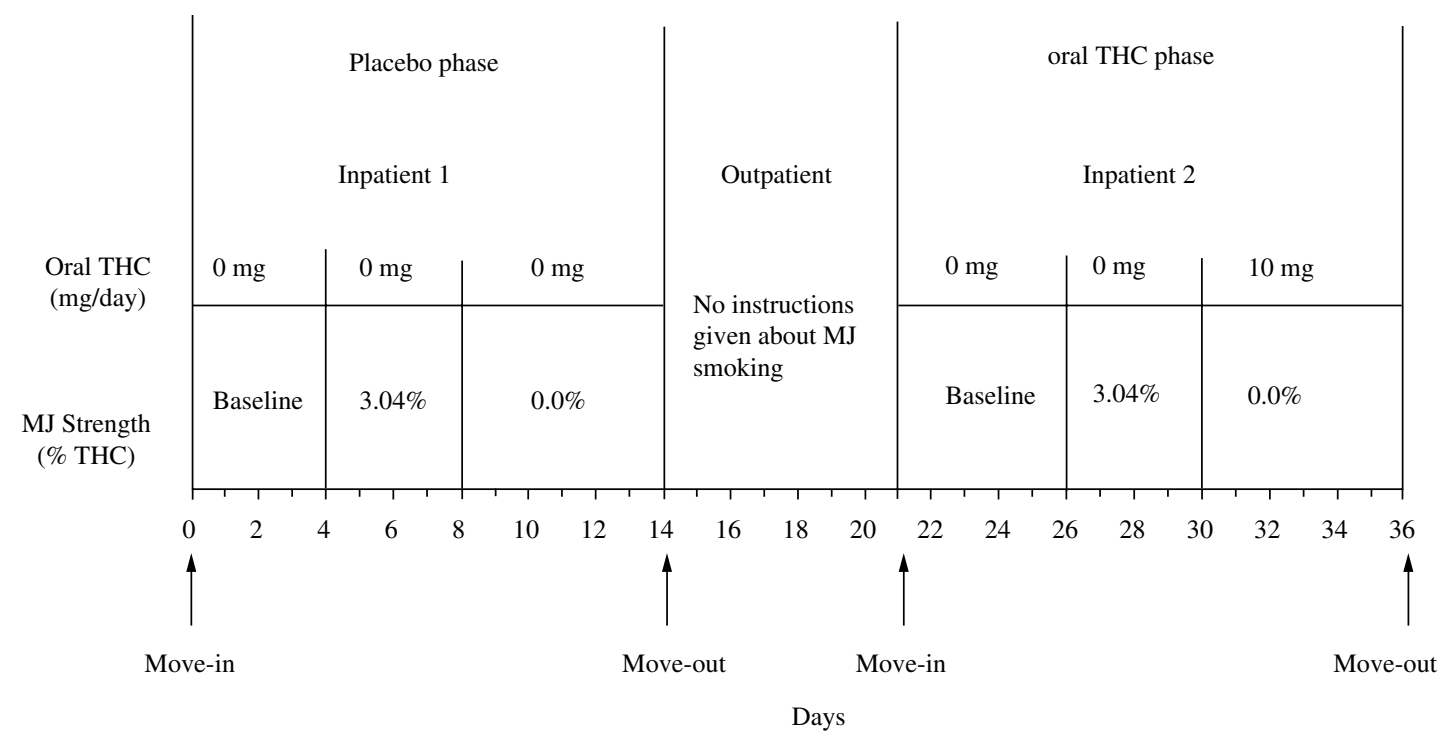

MJ = marijuana. Oral THC dose order counterbalanced across participants. During baseline, placebo marijuana was smoked from I000 to 1900 , when most behavioral data were collected. The final marijuana cigarette at 2300 was active. 
The second administration of marijuana occurred at 1300 . Four task batteries were completed from 1315 to 1645 . The third capsule administration occurred at 1500, and the third marijuana administration occurred at 1600 . Beginning at 1700 , participants again had access to activities available in the recreation area. Two videotaped films were shown each evening. The fourth capsule was administered at 1800, and the fourth marijuana administration occurred at 1900. The fifth capsule administration occurred at 2100, and the fifth marijuana administration occurred at 2200. A six-item Drug-effect Questionnaire was completed on the computer $1 \mathrm{~h}$ after each capsule administration (Evans et al, 1995). A Marijuana Rating Form, consisting of $100-\mathrm{mm}$ lines anchored with 'not at all' on the left and 'extremely' at the right, labeled with: 'Strength of marijuana effect' 'Liking', 'Desire to take again', 'Felt good marijuana effect', 'Felt bad marijuana effect', and whether the marijuana was active or placebo, was completed $45 \mathrm{~min}$ after each marijuana administration. A final VAS and a Marijuana Withdrawal Checklist (modified from a cocaine withdrawal checklist; Brower et al, 1988), in which participants rated the severity in which they experienced 26 symptoms on a 4 -point scale, were completed at 2145 , prior to the final marijuana administration. At 2330, the recreation area was no longer available. Lights were turned off by 2400 .

The first four in-patient days provided a baseline measure of mood and task performance: on these days, the first four daily marijuana cigarettes at 1000, 1300, 1600, and 1900 were placebo $(0.00 \% \mathrm{THC})$, and participants smoked an active marijuana cigarette (3.04\% THC) at 2200 , after all of the mood and performance data had been collected. In this way, participants were not intoxicated while the mood and performance data were collected, but they were also not in a state of prolonged marijuana deprivation (Haney et al, 2003). On in-patient days 5-8, active marijuana was smoked at each of the five time points, while on days 9-14, placebo marijuana was smoked at each time point. Participants moved out of the laboratory on day 15 .

\section{Task Battery}

Each task battery consisted of a 3-min digit-symbol substitution task (DSST), a 3-min repeated acquisition task, a 10-min divided attention task (DAT), a 10-min rapid information task (RIT), an immediate and delayed digitrecall task, and the 50-item VAS. The battery measures various aspects of learning, memory, vigilance, psychomotor ability (see Foltin et al, 1996, for descriptions of the tasks). Participants were instructed to complete each psychomotor task as quickly and as accurately as possible, and to complete the items on the VAS based on how they were feeling at that moment.

\section{Social Behavior}

A computerized observation program was used to record behavior categorically every $2.5 \mathrm{~min}$ during each evening recreation period. Behaviors were divided into two categories: private and social. Private behaviors occurred in each participant's private room or in the bathroom or shower. Social behaviors occurred in the recreation area, and were categorized as being either verbal or nonverbal.

\section{Food}

Every morning at 0830, participants received a box of food containing a variety of meal items, snacks, and beverages that could be consumed at any time within the day. Frozen meal items were also continuously available by request. To facilitate choice of frozen meals, a book containing package pictures of each item was provided. Additional units of any item were freely available upon request. Participants were instructed to scan customdesigned bar codes whenever they ate or drank, specifying substance and portion. At 2330, participants returned their food box to a staff member. Food items were not available between 2330 and 0830 the following morning.

\section{Marijuana Administration}

Participants received their own marijuana cigarette (provided by the National Institute on Drug Abuse) prior to each smoking occasion. Marijuana was administered using a cued-smoking procedure, which has been shown to produce reliable increases in heart rate and plasma levels of THC (Foltin et al, 1987). Colored lights (mounted on the ceiling of the recreation area) signaled 'light the cigarette' (30 s), 'get ready' (5s), 'inhale' (5 s), 'hold smoke in lungs' (10s), and 'exhale.' Participants smoked three puffs in this manner, with a 40 -s interval between each puff; three puffs are often sufficient to pyrolize an entire cigarette. Participants were instructed that they could signal that they wanted to stop smoking by raising their left hand, although no participant did. Cigarettes were tightly rolled at both ends and were smoked through a hollow plastic cigarette holder so the marijuana was not visible. Cigarettes were stored frozen in an airtight container and humidified at room temperature for $24 \mathrm{~h}$ prior to use.

\section{Sleep}

Each night, participants wore the Nightcap ${ }^{\circledR}$ sleep monitoring system (Respironics, Atlanta, GA), which consists of a portable amplifier attached to two leads with adhesive electrodes. One lead attached to the forehead to measure body movement, and the other lead attached to the eyelid to measure eye movement. The Nightcap ${ }^{\circledR}$ was turned on at midnight, when lights were turned off and participants were required to remain in bed. Measures include sleep latency, total sleep time, percentage of time spent in the rapid eye movement (REM) stage of sleep, and body movement. The Nightcap ${ }^{\circledR}$ has been validated using traditional polysomnographic measurement (Ajilore et al, 1995).

\section{Tobacco Cigarette Smoking}

The number of tobacco cigarettes smoked was recorded each evening by counting the remaining cigarette butts in each participant's ashtray. Participants were instructed not to share cigarettes or to throw out cigarette butts, and were monitored to prevent these events from occurring. 


\section{Data Analysis}

Repeated measures analyses of variance (ANOVA) with planned comparisons were used to determine the effect of marijuana $(0.00,3.04 \% \mathrm{THC})$ or oral THC $(0,50 \mathrm{mg} /$ day $)$ during withdrawal from marijuana on subjective effects (average daily ratings), drug effects (average daily ratings), task performance (average daily ratings), social behavior (time spent in private or interacting with other participants), cigarette smoking (number of cigarettes smoked per day), objective sleep measures (total time spent sleeping), food intake (total energy intake), and body weight. There were two within-group factors (THC dose $(0,50 \mathrm{mg} /$ day) and in-patient days (1-14)). Three planned comparisons were made to determine: (1) if there was a marijuana effect (ie baseline $v s$ active marijuana condition); (2) if there was an effect of marijuana withdrawal (ie baseline $v s$ abstinence) during placebo THC maintenance; and (3) if there was an effect of oral THC during withdrawal from marijuana (ie placebo $v s$ active THC during days 9-14). Note that for sleep, food intake, cigarette smoking, and social behavior, there was no placebo baseline condition since participants smoked one active marijuana cigarette $1.5 \mathrm{~h}$ prior to going to sleep. Results were considered statistically significant at $p$-values $<0.05$. Huynh-Feldt corrections were used, when appropriate.

\section{RESULTS: STUDY 1}

\section{Subjective-Effects Ratings}

Figure 1 and Table 2 portray average daily ratings on selected VAS scales during each day of each marijuana condition. Results will be discussed by first describing any significant effects of active marijuana as compared to baseline, followed by the effect of withdrawal from marijuana compared to baseline, and finally the effect of active THC compared to placebo during withdrawal from marijuana. Figure 1 shows that active marijuana significantly decreased ratings of 'Miserable' compared to baseline, while abstinence from marijuana significantly increased ratings of 'Miserable' and 'Chills' under placebo THC conditions. Oral THC decreased ratings of 'Anxiety', 'Miserable', 'Trouble Sleeping', and 'Chills' during marijuana abstinence as compared to placebo.

Table 2 shows that active marijuana significantly increased ratings of 'High' and decreased ratings of 'Irritable' compared to baseline. Withdrawal from marijuana significantly increased ratings of 'Irritable', 'Muscle Pain', and 'Withdrawn', and decreased ratings of 'High', 'Content', 'Friendly', 'Social', 'Mellow', and 'Self-Confident', compared to baseline. Oral THC increased ratings of 'SelfConfident' without affecting any of the other symptoms portrayed in Table 2.

ORAL THC

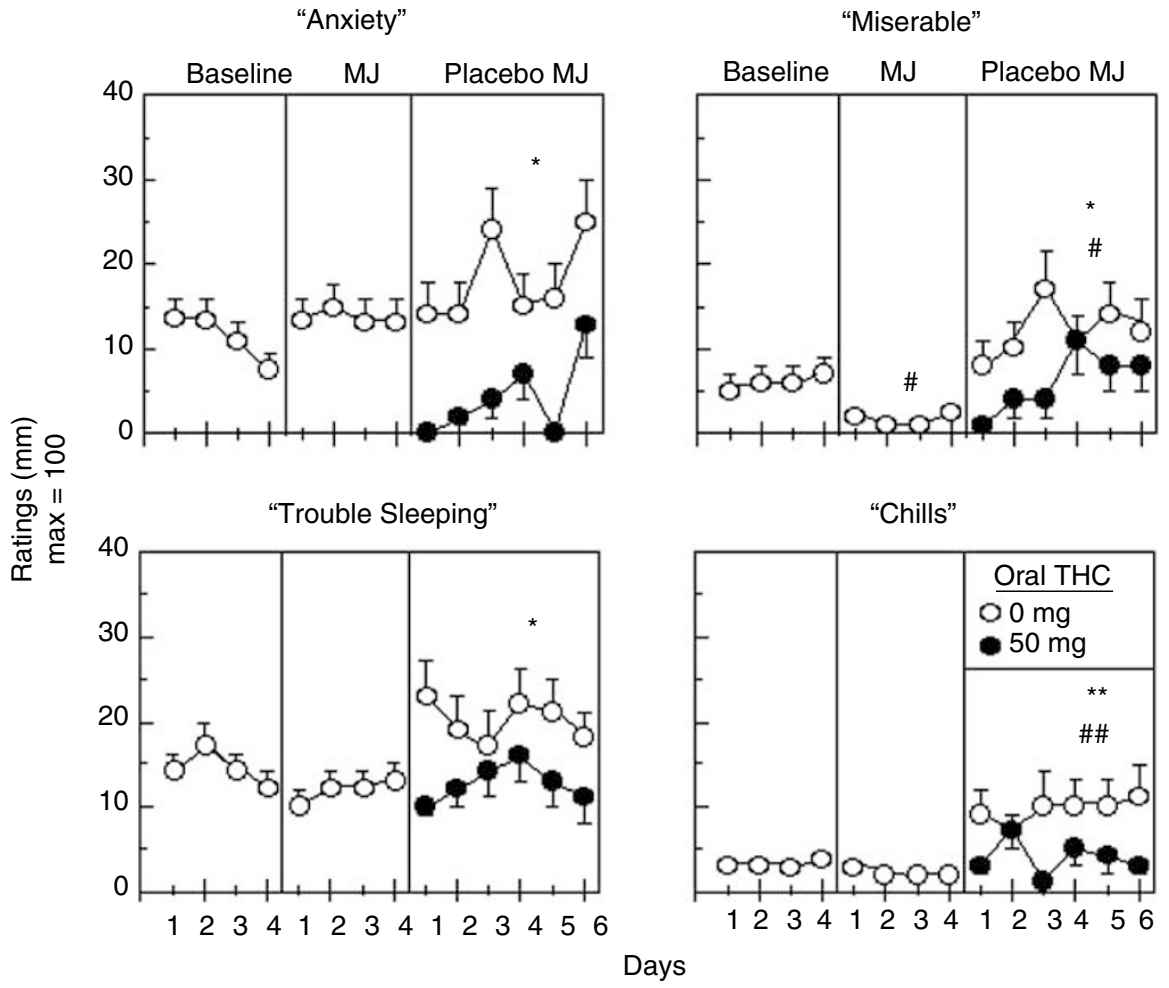

Figure I Selected mean subjective-effect ratings in Study I as a function of oral THC dose and day of the marijuana condition. The open circles represent placebo THC and filled circles represent active THC ( $50 \mathrm{mg} /$ day). In the Baseline condition, placebo marijuana $(0.00 \%$ THC) was smoked during four of the five dosing conditions (1000-1900 h), and an active marijuana cigarette (3.04\% THC) was smoked at 2200 after all mood and physical symptoms questionnaires had already been completed. In the Marijuana (MJ) condition, only active marijuana was smoked at each time points. In the Placebo condition, only placebo marijuana was smoked at each time point. Asterisks indicate a significant difference between oral THC and placebo (* $p<0.05$; $* * 0<0.0 \mathrm{I}$ ). Number signs indicate a significant difference from the Baseline condition during placebo THC administration (\#p<0.05; \#\#p<0.01). Error bars represent \pm standard error of the mean (SEM). 
Table 2 Selected Mean ( \pm SEM) Subjective-Effects Ratings as a Function of Marijuana Condition and THC Dose

\begin{tabular}{|c|c|c|c|}
\hline \multirow[b]{3}{*}{ Baseline } & \multirow[b]{3}{*}{ MJ } & \multicolumn{2}{|c|}{ Placebo MJ } \\
\hline & & \multicolumn{2}{|c|}{ THC Dose } \\
\hline & & $0 \mathrm{mg}$ & $50 \mathrm{mg}$ \\
\hline \multicolumn{4}{|l|}{ High } \\
\hline $5.3(0.9)$ & 介36.6 (2.3)\#\# & $\Downarrow 1.5(0.5) \#$ & $1.4(0.4)$ \\
\hline \multicolumn{4}{|l|}{ Irritable } \\
\hline $10.3(3.4)$ & $\Downarrow 4.1(1.3) \#$ & $\Uparrow 17.8(1.6) \#$ & I5.2(I.7) \\
\hline \multicolumn{4}{|l|}{ Muscle pain } \\
\hline $7.6(2.0)$ & $5.3(1.2)$ & $\Uparrow 15.0(1.5) \# \#$ & $11.9(1.4)$ \\
\hline \multicolumn{4}{|l|}{ Withdrawn } \\
\hline $9.3(2.8)$ & $\Downarrow 2.4(0.8) \#$ & $\Uparrow 22.9(2.0) \# \#$ & | 9.1 (2.0) \\
\hline \multicolumn{4}{|l|}{ Content } \\
\hline $38.6(5.7)$ & $42.9(5.6)$ & $\Downarrow 24.2(1.9) \# \#$ & $22.7(2.0)$ \\
\hline \multicolumn{4}{|l|}{ Friendly } \\
\hline $43.3(3.4)$ & $44.2(3.9)$ & $\Downarrow 31.9(1.5) \#$ & $29.5(1.4)$ \\
\hline \multicolumn{4}{|l|}{ Social } \\
\hline $46.2(3.5)$ & $48.3(3.8)$ & $\Downarrow 36.2(1.5) \#$ & $35.2(1.5)$ \\
\hline \multicolumn{4}{|l|}{ Mellow } \\
\hline $35.2(5.5)$ & $41.8(5.1)$ & $\Downarrow 24.0(1.9) \# \#$ & $22.2(1.9)$ \\
\hline \multicolumn{4}{|l|}{ Self-confident } \\
\hline $72.6(6.2)$ & $74.8(5.7)$ & $\Downarrow 59.3$ (2.4)\#\# & $67.8(2.1)^{*}$ \\
\hline
\end{tabular}

Selected VAS (0-100 mm). Asterisks indicate a significant difference between oral THC and placebo: $* p<0.05, * * p<0.01$. Number signs indicate a significant difference between the Placebo MJ (abstinence) and baseline condition during placebo THC administration; $\# p<0.05, \# \# p<0.01$. Arrows indicate the direction of the change from baseline.

\section{Marijuana Rating Form}

Figure 2, which portrays average daily ratings on selected Marijuana Rating Form scales during each day of each marijuana condition, shows that ratings of marijuana 'Liking' and 'Strength' were significantly increased during the active marijuana condition. Ratings of 'Good Marijuana Effect $(F(1,78)=2068.9, p<0.0001)$ ', and the desire to smoke the marijuana cigarette again $(F(1,78)=14.2$, $p<0.02$ ) showed a similar pattern (data not shown). During abstinence, ratings on all of these measures were significantly decreased compared to baseline. Oral THC did not significantly alter any ratings on the Marijuana Rating Form compared to placebo.

\section{Drug-Effect Questionnaire}

Figure 2 also portrays average daily ratings on selected Drug-Effect Questionnaire scales during each day of each marijuana condition. Ratings of capsule 'Liking', and 'Strength' were significantly increased during the active marijuana condition (despite the fact that only placebo capsules were administered). Ratings of 'Good Drug Effect' showed a similar pattern $(\mathrm{F}(1,78)=16.39, p<0.01$; data not shown). Capsule ratings during abstinence did not sig- nificantly differ from those obtained at baseline. Further, ratings during oral THC administration did not significantly vary from those obtained during placebo administration.

\section{Marijuana Withdrawal Checklist}

Figure 3 (left panel) shows that ratings of 'Craving to smoke marijuana' significantly decreased during active marijuana smoking, and increased during marijuana abstinence, when placebo capsules were administered. Ratings of 'Strange/ wild dreams' also significantly increased during marijuana abstinence. Oral THC decreased ratings of marijuana craving compared to placebo.

\section{Sleep Questionnaire}

Active marijuana significantly increased ratings of 'Fell asleep easily' $(\mathrm{F}(1,78)=5.30, p<0.05)$, while abstinence from marijuana significantly decreased estimates of 'Hours slept' $(\mathrm{F}(1,78)=12.87, p<0.01$; data not shown). Oral THC did not alter any ratings of sleep during marijuana abstinence.

\section{Sleep Monitor}

Data on only five participants were analyzed due to equipment failure in two individuals. There was no significant effect of marijuana, marijuana withdrawal, or oral THC on any of the objective sleep measures. The total time spent sleeping averaged between 5.4 and $7.2 \mathrm{~h}$ per night, regardless of drug condition.

\section{Performance Effects}

Active marijuana decreased performance on the DSST (\% correct) compared to baseline $(\mathrm{F}(1,78)=22.85, p<0.001)$. Marijuana abstinence significantly decreased performance on the DSST (\% correct) $(\mathrm{F}(1,78)=8.46, p<0.05)$, Digit Recognition $(\mathrm{F}(1,78)=6.18, p<0.05)$, and the DAT (mean hit latency: $\mathrm{F}(1,78)=9.96, p<0.01)$ compared to baseline. Oral THC during marijuana abstinence improved performance on two of these tasks: DSST: \% correct $(\mathrm{F}(1,78)=6.42, \quad p<0.05), \quad$ and $\quad$ Digit Recognition $(\mathrm{F}(1,78)=6.16, p<0.05)$. Oral THC impaired performance on the Rapid Integer Task compared to placebo, by increasing the number of false alarms $(\mathrm{F}(1,78)=14.83$, $p<0.01)$.

\section{Food Intake and Body Weight}

As shown in Figure 4 (left panel), the total daily caloric intake was significantly increased by marijuana and decreased during withdrawal from marijuana compared to baseline. Oral THC during withdrawal significantly increased food intake compared to placebo.

Marijuana also significantly increased body weight compared to baseline, and body weight was higher while participants were maintained on oral THC during marijuana abstinence as compared to placebo. Participants were weighed daily. The average weight at baseline was $72.7 \pm 1.0 \mathrm{~kg}$. During active marijuana, weight averaged $74.6 \pm 1.0 \mathrm{~kg}$, while during abstinence and placebo admin- 

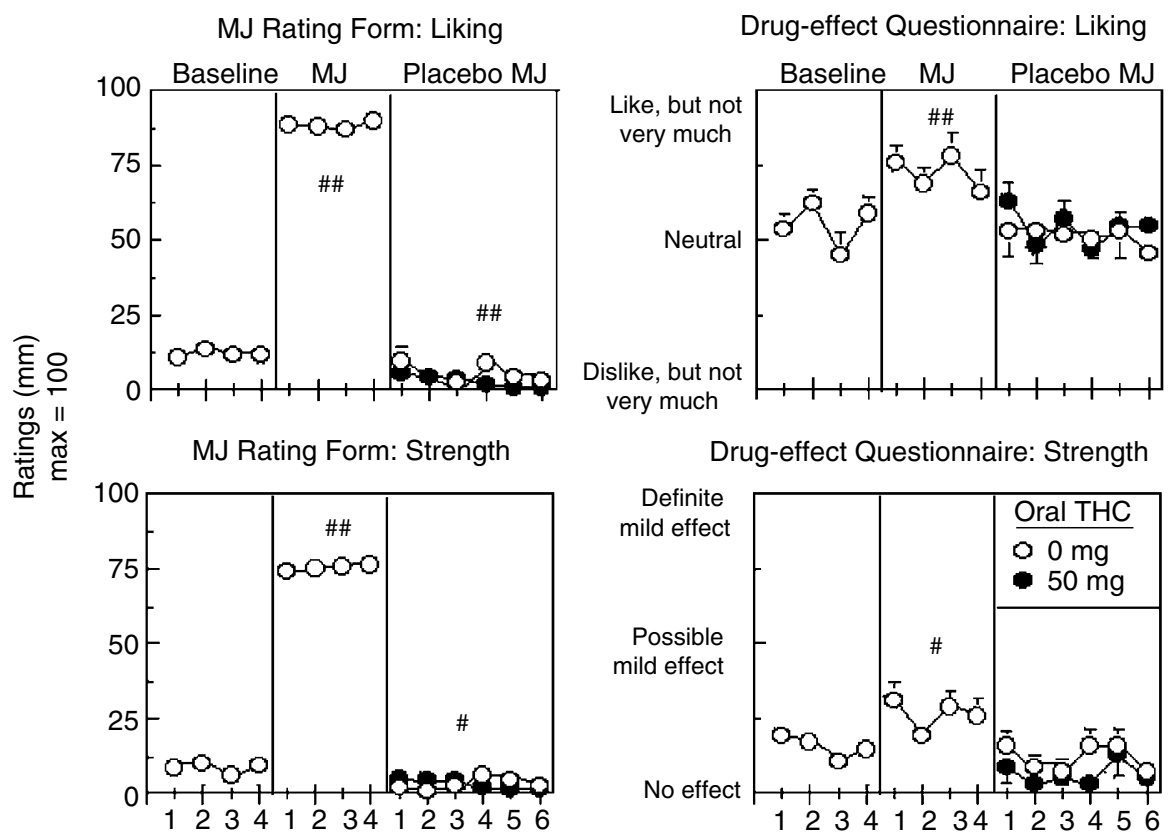

Figure 2 Selected mean ratings on the Marijuana (MJ) Rating Form and Drug-effect Questionnaire in Study I; see Figure I for details.

Craving to Smoke MJ
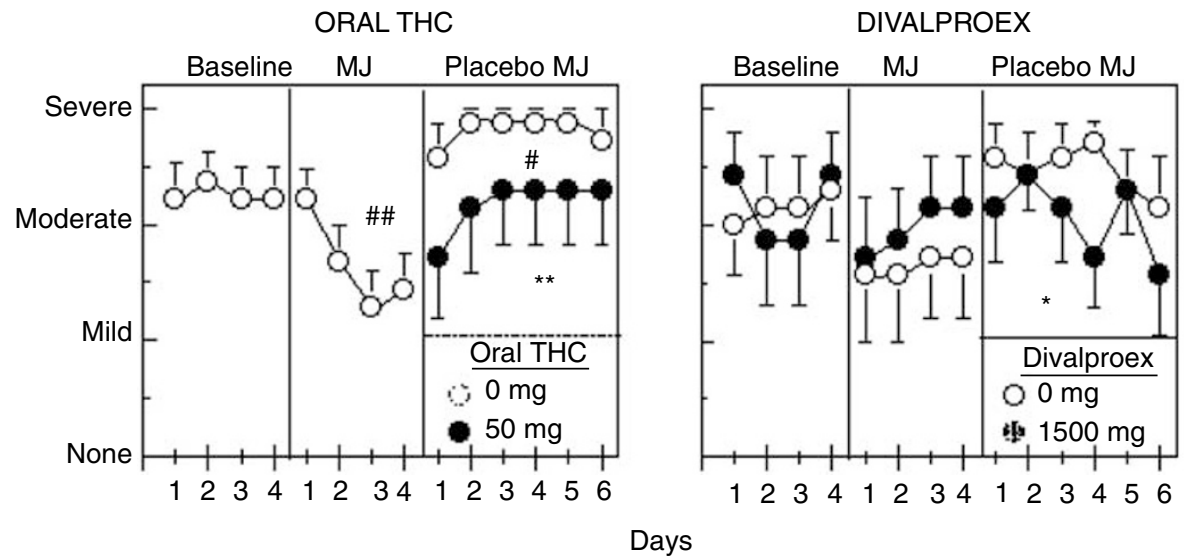

Figure 3 Ratings of marijuana craving from the Marijuana Withdrawal Checklist as a function of oral THC dose (Study I) or divalproex dose (Study 2) and day of the marijuana condition. Details are identical to those described in Figure I.

istration, weight was $72.8 \pm 1.1 \mathrm{~kg}$. Oral THC administration during abstinence increased weight to $74.6 \pm 1.0 \mathrm{~kg}$.

\section{Tobacco Cigarette Smoking}

The six participants who smoked tobacco cigarettes averaged $13.8 \pm 0.3$ cigarettes per day. Neither marijuana condition nor oral THC dose significantly affected the number of tobacco cigarettes smoked.

\section{Social Behavior}

The amount of time that participants spent in private or with at least one other person in the recreation area did not vary as a function of marijuana condition. However, the amount of time participants spent talking in the recreation area during the $390-$ min recreation period was significantly decreased by active marijuana as compared to baseline (baseline, time talking: $96 \pm 16 \mathrm{~min}$; active marijuana, time talking: $28 \pm 8 \mathrm{~min}$ ). During abstinence, oral THC significantly decreased the amount of time spent talking compared to placebo (placebo: $98 \pm 24 \mathrm{~min}$; active marijuana: $73 \pm 25 \mathrm{~min}$ ).

\section{METHODS: STUDY 2}

\section{Participants and Procedures}

One female and six male research volunteers averaging $26 \pm 1$ years (mean \pm SD) completed the 58-day experiment. 
An additional male volunteer (maintained on placebo) left the study during the first in-patient week complaining of stomach acidity. Participants who completed the study reported smoking $6.3( \pm 2.0)$ marijuana cigarettes per day, $6.6( \pm 0.3)$ days per week. Five participants also reported drinking alcohol weekly ( $2.4 \pm 0.7$ days/week, $2.7 \pm 0.6$ drinks/occasion), and four smoked tobacco cigarettes, and continued to do so during the experiment. Other drug use was infrequent. Participants did not diet, were within accepted weight ranges for their heights $(73.3 \pm 12.6 \mathrm{~kg})$, and had no self-reported eating abnormalities.

As shown in Table 3, Study 2 comprised two in-patient and two outpatient phases: an initial 14-day outpatient phase, a 15-day in-patient phase, a second 14-day outpatient phase, and a final 15-day in-patient phase. During the outpatient phases, participants came to the laboratory every weekday to receive their morning dose of divalproex. They were then given their evening dose to be taken at 2100 . On Friday mornings, participants received their evening dose and a 2-day supply of divalproex to be taken each morning and each evening at 0900 and 2100 during the weekend. Compliance was assessed in two ways. First, capsules were packaged with riboflavin, and compliance was assessed qualitatively by examining urine using ultraviolet light detection. Compliance was also assessed quantitatively by plasma assays. The divalproex dose was chosen based on its use in previous studies as a mood stabilizer (eg Levin et al, 2003; Donovan et al, 2000; Giakas et al, 1990). Divalproex dosing started at $500 \mathrm{mg} /$ day, which was increased every 2 days until a final maintenance dose $(1500 \mathrm{mg} /$ day) was achieved on the 9th day of administration. All participants achieved a clinically effective plasma drug level of valproic acid (average: $78.2 \pm 18.6 \mu \mathrm{g} / \mathrm{ml}$ ). For one participant, the divalproex dose was lowered to $1250 \mathrm{mg} /$ day on the 17 th study day as serum valproic acid levels exceeded $100 \mu \mathrm{g} / \mathrm{ml}$. Medication administration was double-blind and counterbalanced. Participants were required to abstain from vitamins, as well as all

Daily Caloric Intake
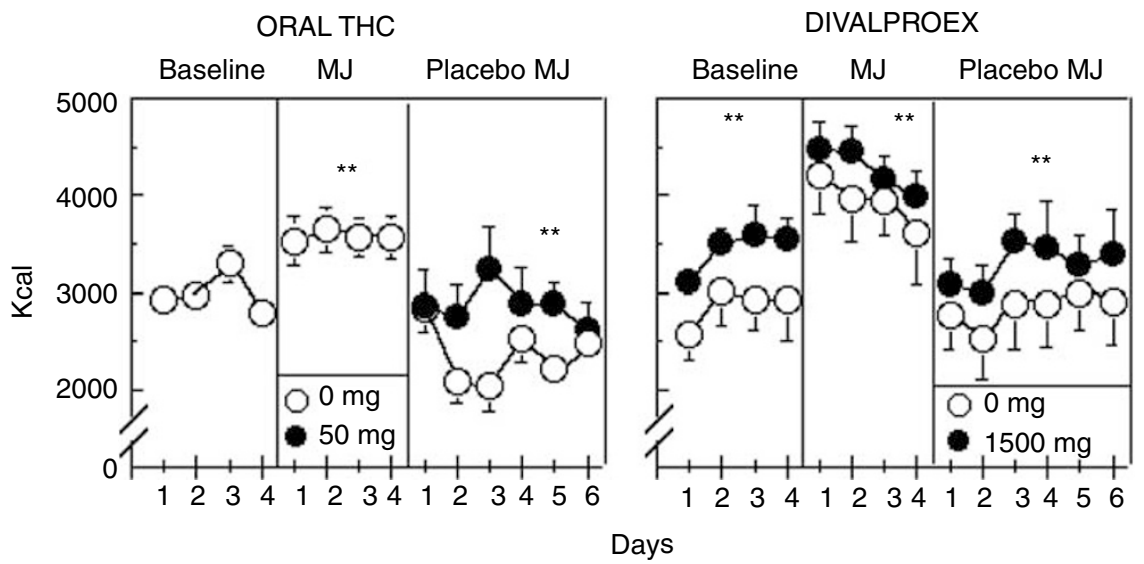

Figure 4 Daily caloric intake for Study I and Study 2 as a function of oral THC dose (Study I) or divalproex dose (Study 2) and day of the marijuana condition. Details are identical to those described in Figure I.

Table 3 Study 2 Timeline

Divalproex phase

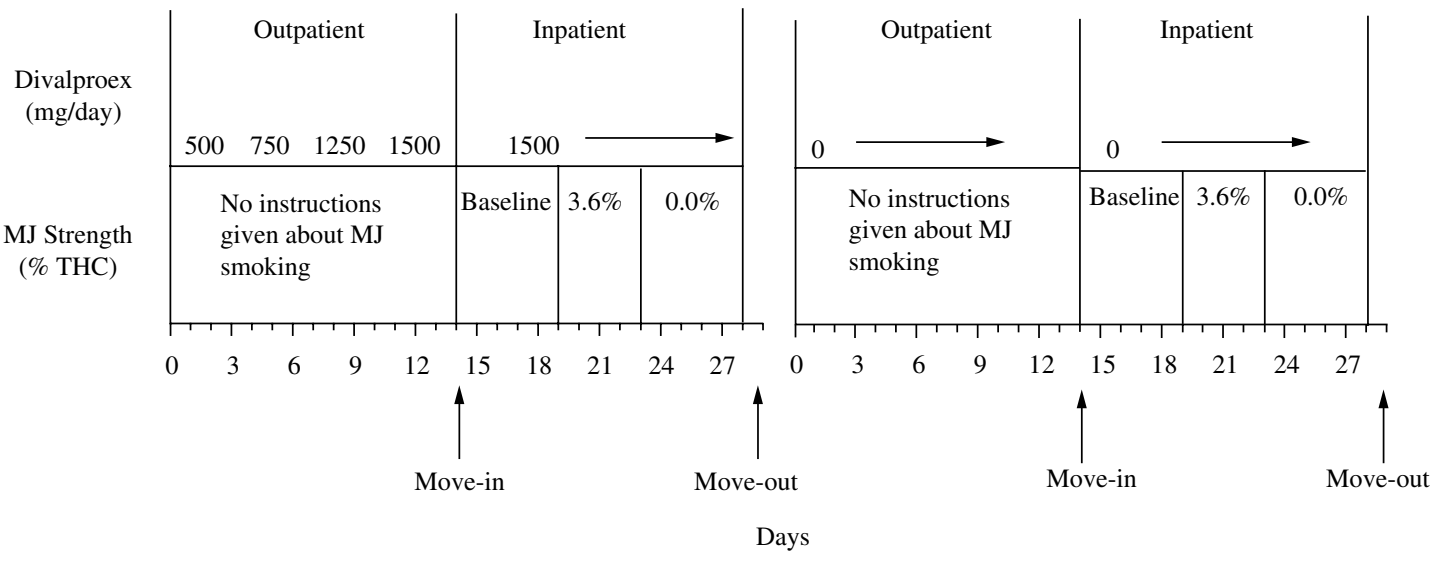

MJ = marijuana; divalproex dose order counterbalanced across participants. 
prescription and over-the-counter medications over the course of the study.

All other details regarding screening and in-patient procedures were identical to Study 1, except that active marijuana cigarette strength was $3.56 \%$ rather than $3.04 \%$ as in Study 1 (due to changes in NIDA's availability), there was no Drug-effect Questionnaire, and the Marijuana Rating Form was completed $60 \mathrm{~min}$ after each marijuana cigarette, rather than $45 \mathrm{~min}$ later.

\section{Data Analysis}

Similar to Study 1, repeated measures ANOVA with planned comparisons were used to determine the effect of divalproex during baseline, during active marijuana administration, and during marijuana withdrawal on subjective effects, drug effects, task performance, social behavior, cigarette smoking, sleep measures, food intake, and body weight. There were two within-group factors (divalproex dose $(0,1500 \mathrm{mg}$ / day) and in-patient days (1-14)). Three planned comparisons were made to determine divalproex's effects across the three marijuana conditions: (1) the 4 days of baseline under placebo and active divalproex were compared; (2) the 4 days of active marijuana administration under placebo and active divalproex were compared; and (3) the 6 days of marijuana withdrawal under placebo and active divalproex were compared. One additional planned comparison was made to determine if there was evidence of marijuana withdrawal by comparing the 4 days of baseline to the 6 days of marijuana abstinence, while participants were maintained on placebo divalproex. Results were considered statistically significant at $p$-values $<0.05$.

\section{RESULTS: STUDY 2}

\section{Subjective-Effects Ratings}

Figure 5 and Table 4 portray the average daily ratings on selected VAS scales during each day of each marijuana condition. Data will be discussed by first describing any significant effects of marijuana abstinence by comparing placebo baseline conditions to placebo abstinence conditions, and then the effect of divalproex under each marijuana condition will be described. Table 4 shows that under placebo divalproex maintenance, ratings of 'Content', 'Mellow', 'Social', 'Energetic', 'Friendly', and 'Talkative' were all decreased during marijuana abstinence compared to baseline. In terms of the effects of maintenance condition during each marijuana condition, divalproex under baseline conditions decreased ratings of 'Content', 'Mellow', 'Social', 'Friendly', and 'Talkative'. During active marijuana smoking, divalproex continued to decrease ratings of 'Talkative', while significantly increasing ratings of 'High' compared to placebo.

Figure 5 demonstrates that divalproex substantially worsened ratings of 'Anxious', 'Irritable', 'On Edge', and 'Sleepy' during marijuana abstinence. Divalproex also increased ratings of 'Withdrawn' and 'Yawning' during marijuana abstinence (Table 4).

\section{Marijuana Withdrawal Checklist}

Ratings of marijuana 'craving' were significantly increased during marijuana abstinence, and decreased by divalproex (Figure 3; right panel).

DIVALPROEX

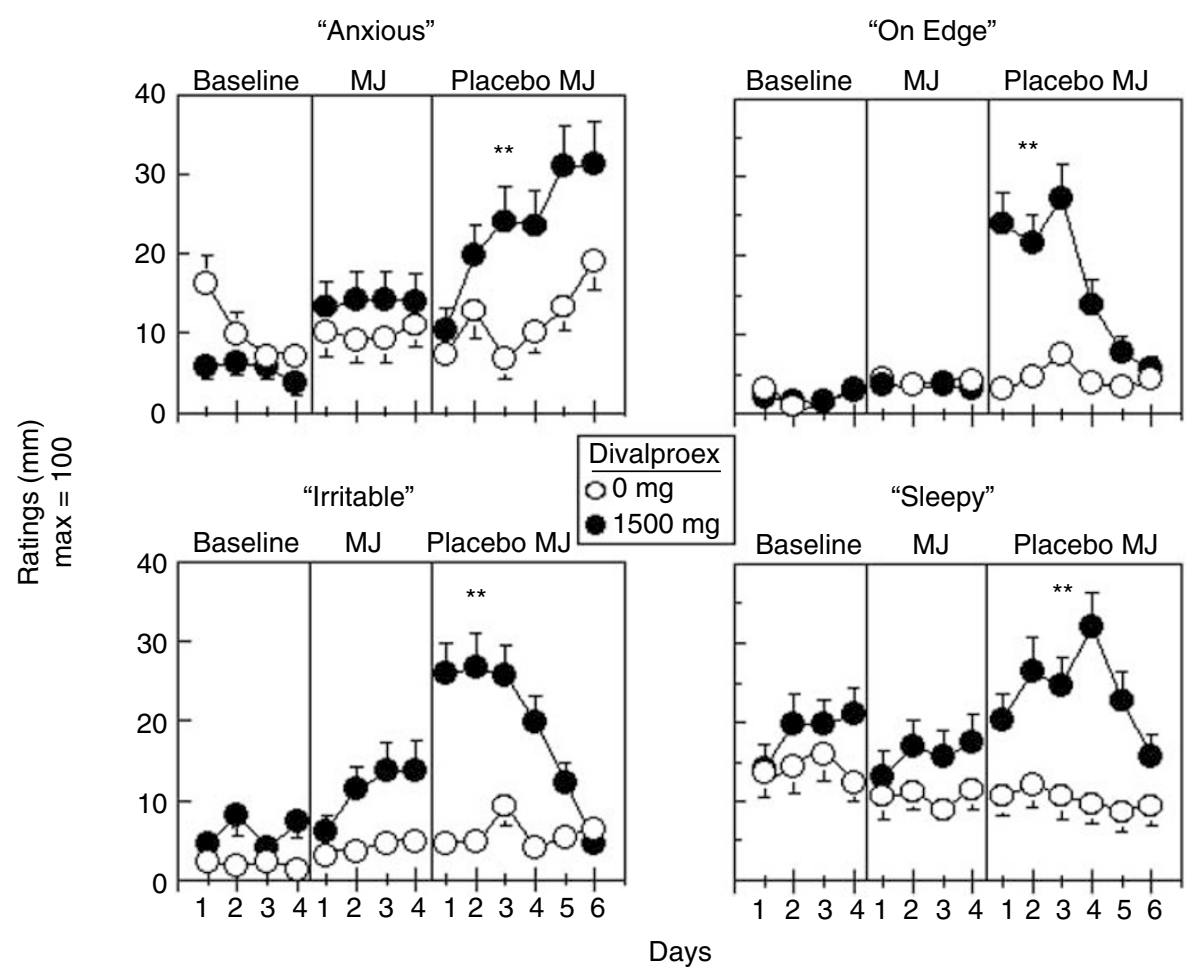

Figure 5 Selected mean subjective-effect ratings in Study 2 as a function of divalproex dose and day of the marijuana condition. Details are identical to those described in Figure I. 
Table 4 Selected Mean ( \pm SEM) Peak Subjective-Effects Ratings as a Function of Marijuana Condition and Divalproex Dose

\begin{tabular}{|c|c|c|c|}
\hline Divalproex & Baseline & MJ & Placebo MJ \\
\hline & & Content & \\
\hline $0 \mathrm{mg}$ & $54.1(1.7)$ & $49.0(2.6)$ & $\Downarrow 46.3(1.8) \#$ \\
\hline \multirow[t]{2}{*}{$1500 \mathrm{mg}$} & $42.9(1.1)^{*}$ & $42.5(1.1)$ & $39.7(1.7)$ \\
\hline & & Mellow & \\
\hline $0 \mathrm{mg}$ & $44.1(1.7)$ & $47.5(1.7)$ & $\Downarrow 31.3(1.6) \# \#$ \\
\hline \multirow[t]{2}{*}{$1500 \mathrm{mg}$} & $29.0(4.1)^{* * *}$ & $40.0(1.0)$ & $32.9(1.1)$ \\
\hline & & Social & \\
\hline $0 \mathrm{mg}$ & $57.0(2.1)$ & $54.0(0.6)$ & $\Downarrow 45.9(1.7) \#$ \\
\hline \multirow[t]{2}{*}{$1500 \mathrm{mg}$} & $46.5(2.7)^{*}$ & $50.8(1.7)$ & $52.2(1.8)$ \\
\hline & & Friendly & \\
\hline $0 \mathrm{mg}$ & $57.4(3.6)$ & $49.6(2.0)$ & $\Downarrow 46.3(1.8) \#$ \\
\hline \multirow[t]{2}{*}{$1500 \mathrm{mg}$} & $45.6(1.7)^{*}$ & $51.4(0.9)$ & $51.6(1.8)$ \\
\hline & & Talkative & \\
\hline $0 \mathrm{mg}$ & $45.8(0.5)$ & $43.9(1.7)$ & $\Downarrow 36.2(1.5) \# \#$ \\
\hline \multirow[t]{2}{*}{$1500 \mathrm{mg}$} & $30.5(1.5)^{* * *}$ & $37.3(0.1)^{*}$ & $32.7(1.2)$ \\
\hline & & High & \\
\hline $0 \mathrm{mg}$ & $4.4(1.7)$ & $21.7(2.0)$ & $3.5(1.2)$ \\
\hline \multirow[t]{2}{*}{$1500 \mathrm{mg}$} & $5.5(1.0)$ & $26.0(0.8)^{*}$ & $5.0(0.5)$ \\
\hline & & Withdrawn & \\
\hline $0 \mathrm{mg}$ & $1.7(0.3)$ & $1.6(0.1)$ & $2.6(0.3)$ \\
\hline \multirow[t]{2}{*}{$1500 \mathrm{mg}$} & $0.7(0.4)$ & $2.0(0.4)$ & $19.9(0.9)^{* * *}$ \\
\hline & & Energetic & \\
\hline $0 \mathrm{mg}$ & $37.6(2.8)$ & $33.0(2.9)$ & $\Downarrow 29.5(2.4) \#$ \\
\hline \multirow[t]{2}{*}{$1500 \mathrm{mg}$} & $36.5(3.4)$ & $35.9(2.2)$ & $31.4(2.8)$ \\
\hline & & Yawning & \\
\hline $0 \mathrm{mg}$ & I5.8 (I.8) & $11.2(1.3)$ & II.7 (0.7) \\
\hline $1500 \mathrm{mg}$ & $17.6(0.6)$ & |2.| (0.4) & $21.4(2.0)^{* * *}$ \\
\hline
\end{tabular}

Data were averaged across the days of each marijuana condition (see Figure I for details of conditions). Asterisks represent significant differences between divalproex maintenance condition; $* 2<0.05, * * * 0.0$ I. Number signs represent significant differences between the baseline and abstinence conditions during placebo maintenance, indicating marijuana withdrawal; \#p<0.05, $\# \# p<0.0$ I. Arrows indicate the direction of the change from baseline).

\section{Performance Effects}

There was no effect of marijuana abstinence on psychomotor task performance as compared to baseline during placebo maintenance. Divalproex substantially worsened performance on numerous psychomotor performance tasks, regardless of marijuana condition, as demonstrated in Figure 6. Specifically, across each marijuana condition, participants completed fewer patterns on the DSST, recognized fewer odd/even number combinations in the Rapid Integer task, and entered fewer sequences on the Repeated Acquisition Task during divalproex maintenance as compared to placebo.

\section{Sleep Questionnaire}

There was no effect of marijuana abstinence on any rating of sleep. During baseline conditions, divalproex significantly increased ratings of 'Woke up early' $(F(1,78)=9.60$, $p<0.01)$ and decreased ratings of 'Hours slept' $(\mathrm{F}(1,78)=6.23, p<0.01)$. During active marijuana, divalproex increased ratings of 'Slept well' $(\mathrm{F}(1,78)=8.23$, $p<0.05)$. During marijuana abstinence, divalproex increased ratings of 'Woke up early' $(\mathrm{F}(1,78)=7.25$, $p<0.01)$, and 'Woke up often' $(\mathrm{F}(1,78)=12.88)$.

\section{Sleep Monitor}

Data on only six participants were analyzed due to equipment failure in one individual. There was no effect of withdrawal from marijuana on any of the objective sleep measures during placebo divalproex maintenance. Divalproex significantly increased the total time sleeping compared to placebo during marijuana abstinence $(\mathrm{F}(1,13)=12.41, p<0.05)$.

\section{Food Intake and Body Weight}

As shown in Figure 4 (right panel), the total daily caloric intake was increased by divalproex regardless of marijuana condition. Divalproex also produced a small but significant increase in body weight during the active marijuana condition $(0.8 \mathrm{~kg})$, and during marijuana abstinence $(0.9 \mathrm{~kg})$.

\section{Social Behavior}

Social behavior was not affected by marijuana abstinence. Divalproex increased the amount of time that participants spent in their private room during marijuana abstinence (placebo divalproex: $61 \pm 3$; divalproex: $78 \pm 6.0 \mathrm{~min}$ ).

\section{DISCUSSION}

The present two studies demonstrate that: (1) oral THC administration beginning on the first day of marijuana abstinence decreased a subset of marijuana withdrawal symptoms compared to placebo administration (Study 1); and (2) maintenance on divalproex prior to and during marijuana abstinence markedly worsened mood, as well as performance on a range of cognitive tasks (Study 2). Data from Study 1 replicated earlier laboratory and clinical studies demonstrating that withdrawal from marijuana is associated with irritability, misery, marijuana craving, and decreased contentment and friendliness. In addition to these mood symptoms, withdrawal from marijuana was also associated with muscle pain, chills, decreased food intake, and decreased self-reported sleep quantity (Haney et al, 1999b, 2001, 2003; Hart et al, 2002b). Compared to placebo, oral THC administered during marijuana abstinence significantly decreased ratings of anxiety, misery, chills, self-reported sleep disturbance, and reversed the anorexia and the weight loss associated with marijuana withdrawal. Oral THC also decreased marijuana craving during abstinence, and improved withdrawal-related decrements in psychomotor task performance. This attenuation of withdrawal symptoms occurred even though participants did not distinguish oral THC capsules from placebo in any mood or capsule rating. These data demonstrate that oral THC attenuates symptoms of withdrawal at doses that produce no apparent subjective effects. The reversal of 


\section{DIVALPROEX}

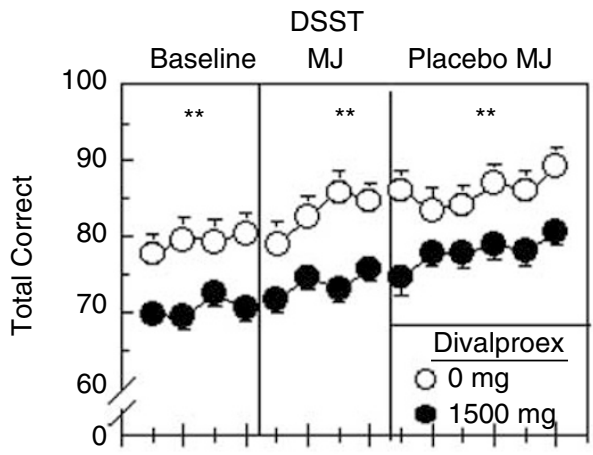

Repeated Acquisition

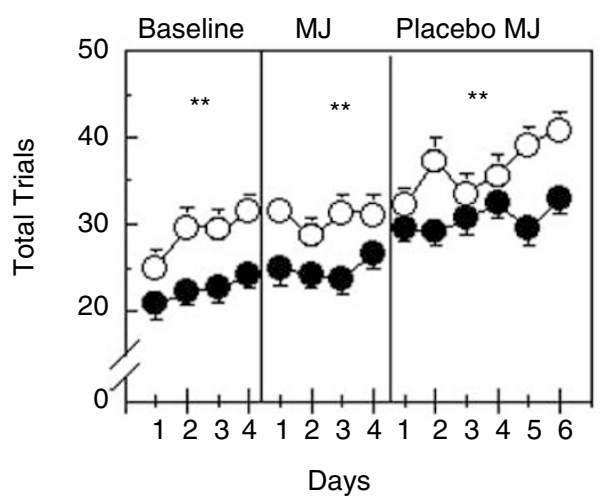

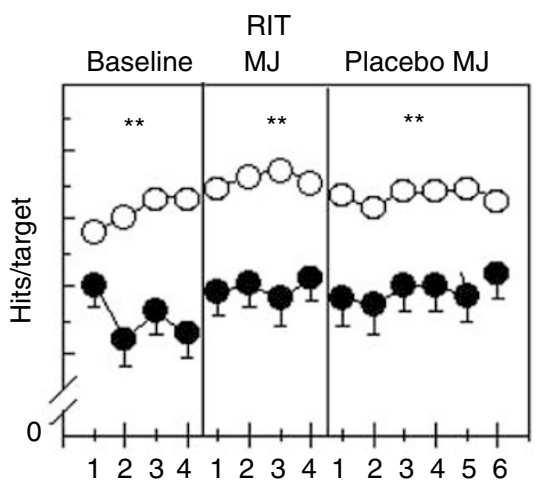

are identical to those described in Figure I.

symptoms by a cannabinoid agonist also further demonstrates the pharmacological specificity of marijuana withdrawal.

Other symptoms of marijuana withdrawal, such as irritability or decreased friendliness and contentment, were unaltered by oral THC. Similarly, maintenance on the antidepressant, nefazodone, attenuated withdrawal symptoms such as muscle pain and anxiety without altering irritability (Haney et al, 2003). It may be that a different dose regimen of oral THC administration would affect a broader range of withdrawal symptoms. Only one active dose of study medication was tested in the present investigation because of the lengthy study design. Given that the current dose of oral THC produced no evidence of intoxication, it would be reasonable to determine whether higher doses of oral THC would modulate a broader range of withdrawal symptoms. Marijuana smokers will vary in their degree of tolerance to the effect of oral THC, so clinicians could individualize the treatment regimen, escalating doses until withdrawal symptoms are reduced and intoxication is minimal. Clearly, the decrease in many symptoms of marijuana withdrawal by oral THC supports further clinical investigation.

We hypothesize that the mechanism by which oral THC would improve marijuana treatment is by decreasing the negative reinforcing effects of marijuana, that is, the return to marijuana use to alleviate symptoms of withdrawal. Marijuana also functions as a positive reinforcer in marijuana smokers. That is, in nonabstinent smokers, active marijuana is self-administered significantly more than placebo marijuana, and increases ratings of 'high' and 'good drug effect' (eg Haney et al, 1997; Ward et al, 1997). Oral THC does not alter these positive reinforcing effects of marijuana: oral THC maintenance $(60,80 \mathrm{mg} /$ day $)$ did not affect marijuana self-administration in individuals who were not in marijuana withdrawal (Hart et al, 2002a). Thus, oral THC may only be an effective treatment medication in abstinent marijuana smokers.

Unlike the agonist approach to treating marijuana withdrawal used in Study 1, Study 2 tested the ability of the mood stabilizer, divalproex, to decrease the negative mood associated with marijuana withdrawal. In fact, divalproex worsened mood ratings of irritability, edginess, anxiety, and sleepiness during abstinence from marijuana, and decreased the amount of time participants chose to spend in a social setting. Divalproex also worsened the subjective impression of sleep: participants reported waking often and waking early, despite the fact that objective measures indicated that divalproex actually increased the total time spent sleeping. Divalproex also produced a number of effects that were independent of the marijuana condition: performance on psychomotor tasks was markedly impaired during divalproex maintenance, whether participants were smoking active or placebo marijuana. Divalproex also increased food intake independent of marijuana, and significantly increased body weight.

It is important to note that the symptoms of marijuana withdrawal were subtle in this sample of marijuana smokers. Although five other in-patient laboratory studies, including Study 1, have demonstrated a consistent pattern 
of mood (irritability, anxiety) and appetite disruption (Haney et al, 1999a, 2001, 2003; Hart et al, 2002b), which corresponds with symptoms reported in outpatient studies, not all individuals experience symptoms of withdrawal. Given this individual variability, one approach to the study of marijuana dependence has been to only enroll individuals reporting to experience withdrawal symptoms (eg Budney et al, 2001), while our approach has been to reflect the entire population of marijuana smokers. Participants in Study 2 rated that they were significantly less content, mellow, friendly, talkative, and social during abstinence compared to baseline. However, the defining features of marijuana withdrawal, such as irritability and decreased food intake, were not observed.

In the absence of robust withdrawal symptoms, it is not possible to conclude definitively that divalproex does not attenuate symptoms of marijuana withdrawal. In fact, divalproex did decrease marijuana craving during abstinence. However, the increased irritability, sleepiness, anxiety, and decreased social interaction during divalproex maintenance is consistent with the poor compliance and negative results obtained in a pilot clinical trial with divalproex (Levin et al, 2003). The impaired cognitive task performance is particularly problematic for a potential treatment medication, as this effect occurred throughout the entire divalproex maintenance period. Laboratory animal data also failed to find an effect with this medication on marijuana withdrawal: precipitated cannabinoid withdrawal in rodents was attenuated by the mood stabilizer lithium, but not by sodium valproate, a constituent of divalproex (Cui et al, 2001). It may be that a lower dose of divalproex would have been less disruptive for a healthy population of marijuana smokers with no psychiatric comorbidity. However, even with the limitations of the present study (one dose tested, small sample size, no female participants), there is little overall to support further investigation of divalproex as a potential treatment medication for marijuana dependence.

Consistent with our earlier studies, marijuana produced large increases in food intake (eg 500-1000 kcal/day) in both Study 1 and Study 2, and decreased social interaction without decreasing the amount of time individuals chose to spend in a social setting (eg Haney et al, 1999b; Foltin and Fischman, 1988; Foltin et al, 1988). Participants in Study 1 also reported sleep disruptions during marijuana withdrawal as compared to baseline (increased ratings of 'trouble sleeping', waking up early and having fewer estimated hours of sleep), which replicates earlier investigations (Budney et al, 2001; Haney et al, 2003). However, these impressions of disrupted sleep were not borne out by objective sleep measures in this study or in a previous study (Haney et al, 2003), suggesting that sleep disruption may not be a symptom of marijuana withdrawal. The differences between subjective and objective measures of sleep are not uncommon, particularly in individuals with mood disorders (Armitage et al, 1997). It may be that the mood symptoms of withdrawal skewed the subjective impression of sleep. Further research on marijuana withdrawal and objective measures of sleep is needed.

To conclude, there are currently no effective pharmacotherapies for cannabinoid dependence (McLellan et al, 2000 ), yet the large number of nonresponders in marijuana treatment studies emphasizes the importance of increasing treatment options for marijuana dependence. We have developed a laboratory model to predict medications that may show promise clinically for the treatment of marijuana dependence. The present findings, in combination with earlier studies, suggest that nefazodone (Haney et al, 2003) and oral THC show promise as potential treatment medications, while bupropion (Haney et al, 2001) and divalproex do not. Future studies will determine if medications that decrease withdrawal also decrease the probability that an abstinent individual will relapse to marijuana use.

\section{ACKNOWLEDGEMENTS}

We thank Brooke Roe, Marcia Soares, Lourdes Roman, and Dr. Erik Gunderson for their excellent assistance in data collection and safety monitoring. We thank the National Institute on Drug Abuse (NIDA) for supplying the marijuana cigarettes. This research was supported by the US National Institute on Drub Abuse (DA09236).

\section{REFERENCES}

Ajilore O, Stickgold R, Rittenhouse CD, Hobson JA (1995). Nightcap: laboratory and home-based evaluation of a portable sleep monitor. Psychophysiology 32: 92-98.

Apelt S, Emrich HM (1990). Sodium valproate in benzodiazepine withdrawal. Am J Psychiatry 147: 950-951.

Armitage R, Trivedi M, Hoffmann R, Rush AJ (1997). Relationship between objective and subjective sleep measures in depressed patients and healthy controls. Depression Anxiety 5: 97-102.

Boyd S, Gorelick D, Huestis M, Heishman S, Dermand JC, Nides MA et al (2002). Prevalence and persistence of withdrawal symptoms reported by a non-treatment sample of marijuana smokers. Drug Alcohol Depend 66: S19.

Brady KT, Myrick H, Henderson S, Coffey SF (2002). The use of divalproex in alcohol relapse prevention: a pilot study. Drug Alcohol Depend 67: 323-330.

Brower KJ, Maddahian E, Low FC, Beresford TP (1988). A comparison of self-reported symptoms and DSM-III-R criteria for cocaine withdrawal. Am J Drug Alcohol Abuse 14: 347-356.

Budney AJ, Higgins ST, Radonovich KJ, Novy PL (2000). Adding voucher-based incentives to coping skills and motivational enhancement improves outcomes during treatment for marijuana dependence. J Consult Clin Psychol 68: 1051-1061.

Budney AJ, Hughes JR, Moore BA, Novy PL (2001). Marijuana abstinence effects in marijuana smokers maintained in their home environment. Arch Gen Psychiatry 58: 917-924.

Budney AJ, Moore BA, Vandrey RA, Hughes JR (2002). Onset, magnitude, and duration of abstinence effects following heavy marijuana use. Drug Alcohol Depend 66: S23.

Budney AJ, Novy PL, Hughes JR (1999). Marijuana withdrawal among adults seeking treatment for marijuana dependence. Addiction 94: 1311-1321.

Budney AJ, Radonovich KJ, Higgins ST, Wong CJ (1998). Adults seeking treatment for marijuana dependence: a comparison with cocaine-dependent treatment seekers. Exp Clin Psychopharmacol 6: 419-426.

Copeland J, Swift W, Roffman R, Stephens R (2001). A randomized controlled trial of brief cognitive-behavioral interventions for cannabis use disorder. J Subst Abuse Treatment 21: 55-64.

Cui S-S, Bowen RC, Gu G-B, Hannesson DK, Yu PH, Zhang X (2001). Prevention of cannabinoid withdrawal syndrome by 
lithium: involvement of oxytocinergic neuronal activation. J Neurosci 21: 9867-9876.

Dole VP (1988). Implications of methadone maintenance on theories of narcotic addiction. JAMA 260: 3025-3029.

Donovan SJ, Stewart JW, Nunes EV, Quitkin FM, Parides M, Daniel $\mathrm{W}$ et al (2000). Divalproex treatment for youth with explosive temper and mood lability: a double-blind, placebo-controlled, crossover design. Am J Psychiatry 157: 818-820.

Ellis BW, Johns MW, Lancaster R, Raptopoulos P, Angelopoulos N, Priest RG (1981). The St Mary's hospital sleep questionnaire. Sleep 4: 93-97.

Evans SM, Foltin RW, Levin FR, Fischman MW (1995). Behavioral and subjective effects of DN-2327 (pazinaclone) and alprazolam in normal volunteers. Behav Pharmcol 6: 176-186.

Foltin RW, Fischman MW (1988). Effects of smoked marijuana on human social behavior in small groups. Pharmacol Biochem Behav 30: 539-541.

Foltin RW, Fischman MW, Byrne MF (1988). Effects of smoked marijuana on food intake and body weight of humans living in a residential laboratory. Appetite 11: 1-14.

Foltin RW, Fischman MW, Pedroso JJ, Pearlson GD (1987). Marijuana and cocaine interactions in humans: cardiovascular consequences. Pharmacol Biochem Behav 28: 459-464.

Foltin Rw, Haney M, Comer SD, Fischman MW (1996). Effect of ferfluramine in food intake, mood and performance of humans living in a residential laboratory. Psysiol Behav 59: 295-305.

Giakas WJ, Seibyl SP, Mazure CM (1990). Valproate in the treatment of temper outbursts. J Clin Psychiatry 51: 525.

Haney M, Comer SD, Ward AS, Foltin RW, Fischman MW (1997). Factors influencing marijuana self-administration by humans. Behav Pharmacol 8: 101-112.

Haney M, Hart CL, Ward AS, Foltin RW (2003). Nefazodone decreases anxiety during marijuana withdrawal in humans. Psychopharmacology 165: 157-165.

Haney M, Ward AS, Comer SD, Foltin RW, Fischman MW (1999a). Abstinence symptoms following oral THC administration to humans. Psychopharmacology 141: 385-394.

Haney M, Ward AS, Comer SD, Foltin RW, Fischman MW (1999b). Abstinence symptoms following smoked marijuana in humans. Psychopharmacology 141: 395-404.
Haney M, Ward AS, Comer SD, Hart CL, Foltin RW, Fischman MW (2001). Bupropion SR worsens mood during marijuana withdrawal in humans. Psychopharmacology 155: 171-179.

Hart CL, Haney M, Ward AS, Fischman MW, Foltin MW (2002a). Effects of oral THC maintenance on smoked marijuana selfadministration. Drug Alcohol Depend 67: 301-309.

Hart C, Ward AS, Haney M, Comer SD, Foltin RW, Fischman MW (2002b). Comparison of smoked marijuana and oral d9tetrahydrocannabinol in humans. Psychopharmacology 164: 407-415.

Kouri EM, Pope Jr HG (2000). Abstinence symptoms during withdrawal from chronic marijuana use. Exp Clin Psychopharm 8: 483-492.

Levin FR, McDowell D, Evans SM, Akerele E, Donovan S, Nunes E (2003). Pharmacotherapy for marijuana dependence: a doubleblind, placebo-controlled pilot study of divalproex sodium. $\mathrm{Am} \mathrm{J}$ Addict (in press).

McLellan AT, Lewis DC, O'Brien CP, Kleber HD (2000). Drug dependence, a chronic medical illness. JAMA 284: 1689-1695.

Roffman RA, Stephens RS, Simpson EE, Whitaker DL (1988). Treatment of marijuana dependence: preliminary results. J Psychoactive Drugs 20: 129-137.

SAMHSA (1999). Treatment episode data set, national admission to substance abuse treatment services 1992-1997. Rockville MD: Drug and Alcohol Services. Information System Series 5-7.

Shiffman S, Johnston JA, Khayrallah M, Elash CA, Gwaltney CJ, Paty JA et al (2000). The effect of bupropion on nicotine craving and withdrawal. Psychopharmacology 148: 33-40.

Stephens RS, Roffman RA, Curtin L (2000). Extended versus brief treatment for marijuana use. J Consult Clin Psychology 68: 898-908.

Stephens RS, Roffman RA, Simpson EE (1993). Adult marijuana users seeking treatment. J Consult Clin Psychol 61: 1100-1104.

Stephens RS, Roffman RA, Simpson EE (1994). Treating adult marijuana dependence: a test of the relapse prevention model. J Consult Clin Psychology 62: 92-99.

Ward AS, Comer SD, Haney M, Foltin RW, Fischman MW (1997). Effects of monetary alternatives on marijuana self-administration by humans. Behav Pharmacol 8: 275-286. 